\section{Dos obras sobre investigación comprometida de interés para el campo del aprendizaje servicio}

\section{Reseña}

\section{Enrique Ochoa}

\section{CLAYSS, Argentina}

Si bien los conceptos de "engaged research" o "community based research" tienen mucho que ver con la corriente de la investigación-acción surgida en la década de 1970 en América Latina, estos no siempre se vinculan explícitamente con la pedagogía del aprendizaje servicio.

Sin embargo, el interés de las dos obras que se reseñan aquí radica en que la dimensión de la investigación es parte central del itinerario de un proyecto de aprendizaje servicio de calidad, tanto como parte de los procesos diagnósticos como de evaluación, y muchas veces como parte de la respuesta a necesidades planteadas por la comunidad.

Especialmente en la educación superior, pero incluso para las investigaciones escolares, los conceptos de investigación-acción, investigación comprometida o basada en la comunidad son esenciales para sustentar buenas prácticas de aprendizaje servicio. Una tentación frecuente es la de divulgar los conocimientos académicos producidos en la universidad y reproducidos en la escuela, sin establecer las necesarias mediaciones y diálogos con los saberes previos de la comunidad, con los saberes populares y ancestrales que pueden enriquecer y a menudo desafiar a los conocimientos producidos en el ámbito académico formal.

Por ello estas obras pueden ser de suma utilidad para la comunidad de investigadores y protagonistas de proyectos de aprendizaje servicio.

Tandon, R.; Hall, B.; Lepore, W y Singh, W. (eds) (2016) Knowledge and Engagement. Building Capacity for the Next Generation of Community Based Researchers. UNESCO Chair in Community Based Research and Social Responsibility in Higher EducationUniTwin, University of Victoria, PRIA

Rajesh Tandon (PRIA, India) y Budd Hall (Victoria University, Canadá) son los titulares de la Cátedra UNESCO de Investigación basada en la comunidad y Responsabilidad Social en la Educación Superior, y los compiladores -junto a Walter Lepore y Wafa Singh- de esta obra, que reúne contribuciones de más de 40 autores de todo el mundo.

La obra incluye un marco teórico, los resultados de una encuesta mundial, 21 estudios de casos, y un análisis comparativo de esos casos.

El aprendizaje servicio es mencionado varias veces en la obra como un espacio de vinculación entre la investigación en comunidad y los contenidos curriculares, pero sin profundizar en el tema. aprendizaje servicio. RIDAS, Revista Iberoamericana de Aprendizaje Servicio, 3, 166-169. 
Este libro digital de descarga gratuita presenta un escenario actual de gran diversidad y proporciona una serie de recomendaciones basadas en las prácticas, orientadas específicamente a investigadores universitarios, pero que puede ser de utilidad a todos los involucrados en proyectos de aprendizaje-servicio.

El libro completo en inglés se puede descargar aquí; http://unescochaircbrsr.org/pdf/resource/Knowledge\%20\& \%20Engagement_26-09-

16_pdf\%20ver-mail.pdf

Campus Engage Irish Universities Association (2016) Engaged Research. Society and Higher Education. Addressing Grand Societal Challenges Together. Dublín: Campus Engage

Campus Engage Irlanda desarrolló el informe Investigación Comprometida: Sociedad y Enseñanza Superior. Trabajando juntos para enfrentar grandes desafíos sociales, elaborado por un grupo de trabajo de expertos irlandeses y financiado por el Irish Research Council.

Campus Engage es una red que asocia a las universidades irlandesas que promueven el compromiso social, y promueve explícitamente el aprendizaje servicio.

La obra abarca dentro del término de investigación comprometida una amplia gama de enfoques y metodologías de investigación que comparten un interés común en el compromiso colaborativo con la comunidad y apuntan a mejorar, comprender o investigar temas de interés público, incluyendo desafíos sociales. Entre ellos, se incluye explícitamente al aprendizaje Servicio, denominado "community servicelearning", como uno de los descriptores utilizados para mapear el estado de la cuestión de la investigación comprometida en Irlanda.

Este informe ofrece un marco transdisciplinario inclusivo para la investigación comprometida y su impacto, acordado entre las universidades irlandesas pero seguramente de interés para otros contextos.

La obra se puede descargar en inglés aquí:

http://www.campusengage.ie/sites/def ault/files/FINAL\%20JAN\%2016_ER\%20 Report\%202016\%20Jan\%20v2.pdf

Otras publicaciones de interés

Fiorin, I. (2016). Oltre I'aula. La proposta pedagogica del servicelearning. Milano: Mondadori Università.

Si bien la pedagogía del aprendizaje servicio se viene desarrollando en diversas instituciones italianas desde hace más de una década, en los últimos años ha cobrado nuevo impulso.

Recientemente ha sido publicado en Italia la primera obra del Centro de Altos Estudios EIS (Educación, Inclusión, Solidaridad) de la Universidad LUMSA de Roma. El libro, dirigido por Italo Fiorin, incluye dos presentaciones, 
una a cargo de Nieves Tapia, sintetizando los desarrollos internacionales e italianos del aprendizaje servicio en la última década, y otro a cargo del ex-Ministro de educación italiano Luigi Berlinguer.

La obra incluye aportes y reflexiones a cargo de Italo Fiorin, Giuseppe Milan y Carina Rossa, así como una síntesis de experiencias de escuelas italianas sistematizadas por Simone Consegnati, y un capítulo sobre la difusión del aprendizaje servicio en España a cargo de Roser Batlle.

El libro concluye con una antología de textos relevantes de autores como Jorge Bergoglio, John Dewey, Andrew Furco, Howard Gardner, Paulo Freire y otros.

Si bien los autores han optado por utilizar el término inglés servicelearning en lugar del italiano apprendimento-servizio empleado en obras anteriormente publicadas en Italia ${ }^{1}$, del conjunto del libro emerge una visión más cercana a la visión iberoamericana del aprendizaje servicio que al encuadre anglosajón.

Manuales sobre aprendizaje servicio con experiencias de instituciones educativas uruguayas

\footnotetext{
${ }^{1}$ Cf. Studium Educationis, rivista per la formazione nelle professioni educative. Pedagogia Sociale del disagio e della devianza. Anno IX N.2 Maggio-Agosto 2004, Padova. Tapia, María Nieves. Educazione e solidarietà. La pedagogia dell' apprendimento-servizio. Roma, Città Nuova, 2006
}

Publicados por CLAYSS para su sede de Uruguay, estos manuales pueden ser útiles también para docentes de otras latitudes. Los manuales presentan una breve síntesis conceptual, y desarrollan los pasos y procesos transversales de un itinerario posible para el desarrollo de proyectos escolares de aprendizaje servicio solidario, ejemplificados con experiencias de escuelas y liceos uruguayos. Los manuales se orientan en a instituciones de educación inicial y primaria en un caso, y en el otro a la educación media.

Pueden descargarse gratuitamente en http://www.clayss.org.ar/uruguay/1_Ini cial-Primario.pdf (inicial y primaria) y en http://www.clayss.org.ar/uruguay/2 Se cundario.pdf (secundaria y técnica).

Manual de aprendizaje servicio del Ministerio de Educación de Chile

Este breve y excelente Manual de aprendizaje servicio fue publicado originalmente por el Ministerio de Educación chileno en el año 2007. Los avatares de los cambios políticos lo mantuvieron encerrado en los depósitos ministeriales casi 10 años, pero finamente está nuevamente a disposición de los docentes chilenos y de quienes les interese descargarlo gratuitamente on line.

La obra, coordinada por Jorge Castillo, Daniela Eroles y Valentina Sánchez, no ha perdido actualidad, e incluye un marco conceptual, una guía para el desarrollo de proyectos y un apéndice con buenas prácticas de escuelas aprendizaje servicio. RIDAS, Revista Iberoamericana de Aprendizaje Servicio, 3, 166-169. 
chilenas.

Es de destacar que Chile está

reintroduciendo en el currículo escolar

la asignatura de Formación para la

Ciudadanía, que tendrá un claro

componente de aprendizaje servicio. El

manual puede descargarse aquí:

http://www.clayss.org.ar/04_publicacio

nes/manual-de-aprendizaje-

mineduc2007.pdf 